Radio and Optical Observations of "Optically quiet quasars"

W. D. Cotton, F. N. Owen

National Radio Astronomy Observatory

M. J. Mahoney

Clark Lake Radio Observatory

1. Introduction

In recent years a number of very steep spectrum, compect radio sources have been discovered (e.g. Cotton 1983, Cotton and Owen 1985, Ulvestad 1985) which have no optical counterpart to the limit of the Palomar SkY Survey. VLBI observations of a number of these have confirmed the very compect ( 10 mas) nature of several of these sources. Analysis of the avatlable data in terms of the standard synohrotron model suggest that they contain very woek magnetio fields, large partiale densities and may emit detectable infrared and opticel emission by inverse compton scattering in the compect radio source (Cotton 1983). This paper will report on an anolysis inaluding new VLBI abservations, infrared and opticel imaging at KPIO and low frequency radio abservations at CLRO of a number of these abjects.

\title{
2. Analysis
}

Important physical parameters cen be derived for a synahrotron emitting source from abservations of the spectrum and size of the source. In particular, the magnetio field strength and relativistio electron densities derived for the sources under consideration (see Marscher 1983) indicate wook magnetio fields and large relativistio electron densities. Under these conditions inverse Compton scattering of the radio photons off the relativistio electrons becomes important. Table 1 shows the abserved and derived parameters for several abjects; minimum gamma is the minimum bulk relativistio factor for which the model does not violate the data and B corresponds to this model.

Table 1

Observed and derived source parameters

\begin{tabular}{|c|c|c|c|c|c|}
\hline Souroe & $\begin{array}{l}\text { Size } \\
\text { mas }\end{array}$ & $\begin{array}{c}\text { Max. freq. } \\
\text { MHz }\end{array}$ & $\underset{\text { mJy }}{\text { Max flux }}$ & $\begin{array}{c}\text { Min gamma } \\
(z=0)\end{array}$ & $\begin{array}{c}\text { B } \\
\text { mgeuss }\end{array}$ \\
\hline $\begin{array}{l}0752+342 \\
1015+345 \\
1621+347 \\
2147+145\end{array}$ & $\begin{array}{r}11 . \\
6 . \\
17.2 \\
5.8\end{array}$ & $\begin{array}{r}<100 \\
<100 \\
100 \\
150\end{array}$ & $\begin{array}{r}>2000 \\
>400 \\
2000 \\
3200\end{array}$ & $\begin{array}{r}4.6 \\
2.9 \\
2.5 \\
24 .\end{array}$ & $\begin{array}{r}<3.3 \mathrm{E}-3 \\
<4.8 \mathrm{~B}-3 \\
1.1 \mathrm{E}-2 \\
1.2 \mathrm{E}-3\end{array}$ \\
\hline
\end{tabular}


Figure 1 shows the abserved speotrum of $2147+145$ and several synahtron model computations intended to reproduce the observed spectrum and size. The dotted line is a model inaluding only symahrotron processes; the dashed Iine is the same model but inaluding the effects of Compton scattering. This latter model shows that most of the radio photons have been scattered to higher frequenates. The soltd line shows a model inaluding relativistio beaming with a bulk relativistio factor of 24 (assuming $z=0$; 48 if $z=1$ ) which is in reasonable agreement with the data. Clearly, the only realistic symohrotron model which adequately reproduces the abservations is the relativistio beaming case. There is, however, no direct evidence that the emission is from the synohrotron process.

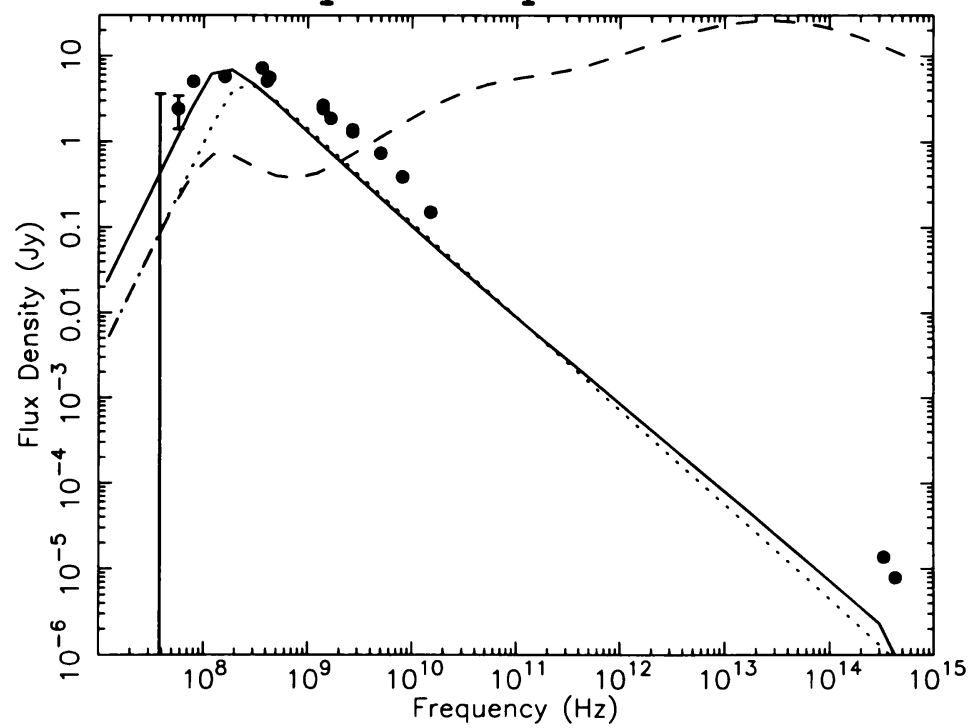

Figure 1 - Observed spectrum and synahrotron models for $2147+145$.

\section{Conolusions}

A number of steep spectrum, compact, optically weak radio sources have been abserved which aennot be modeled by synohrotron emission from a non-moving source. The sources an be adequately modeled by a synobrotron emitting source moving towards us at highiy relativistio veloalties. Another posstibility requiring serious attention is that the emission may not be produced by the synahrotron process.

\section{REFERERTESS}

Cotton, W. D., 1883, Ap. J., 271, 51.

Cotton, W. D. and Oren, F. N., 1885, unpublished results.

Marscher, A. P. 1883, Ap. J., 264, 286.

Ulvestadt, J. M., 1885, Ap. J., 288, 514. 


\section{DISCUSSION}

Burbidge : Are they galactic stars ?

Cotton : Probably not; several of the objects have only a stellar like component but several also have significant levels of fuzz. The one object with a good VLBI image, $2147+145$, has a core - "jet" structure similar to quasars. There is no direct evidence that these are not stars.

Coleman : Could you say what Lorentz factor is required when fitting a synchrotron self-compton model to the low optical flux.

Cotton : If the object is at $z \simeq 0, \gamma=25$ is required, but for $z \simeq 1$ it is $\gamma=50$. 